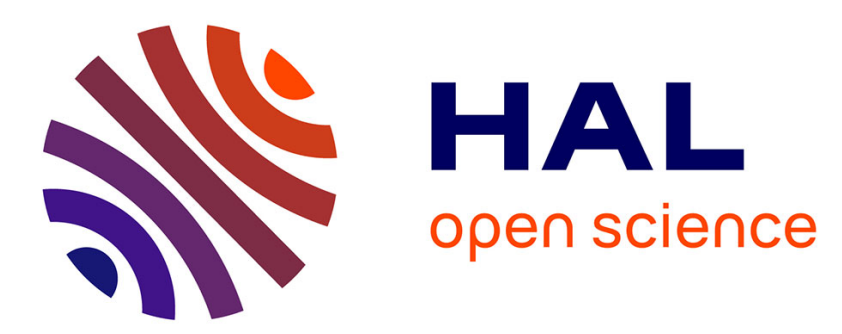

\title{
ATMOSPHERIC CLIMATE CONTROL OF DIRECTIONAL WAVES IN THE UNITED KINGDOM AND IRELAND
}

Tim Scott, Mark Wiggins, Gerd Masselink, Bruno Castelle, Guillaume Dodet, Andy Saulter

\section{- To cite this version:}

Tim Scott, Mark Wiggins, Gerd Masselink, Bruno Castelle, Guillaume Dodet, et al.. ATMOSPHERIC CLIMATE CONTROL OF DIRECTIONAL WAVES IN THE UNITED KINGDOM AND IRELAND. Coastal Sediments'19, May 2019, Tampa, United States. 10.1142/9789811204487_0063 . hal-02394968

\section{HAL Id: hal-02394968 https://hal.science/hal-02394968}

Submitted on 11 Dec 2019

HAL is a multi-disciplinary open access archive for the deposit and dissemination of scientific research documents, whether they are published or not. The documents may come from teaching and research institutions in France or abroad, or from public or private research centers.
L'archive ouverte pluridisciplinaire HAL, est destinée au dépôt et à la diffusion de documents scientifiques de niveau recherche, publiés ou non, émanant des établissements d'enseignement et de recherche français ou étrangers, des laboratoires publics ou privés. 


\title{
ATMOSPHERIC CLIMATE CONTROL OF DIRECTIONAL WAVES IN THE UNITED KINGDOM \& IRELAND
}

\author{
TIM SCOTT $^{1}$, MARK WIGGINS ${ }^{1}$, GERD MASSELINK ${ }^{1}$, BRUNO CASTELLE $^{2}$, \\ GUILLAUME DODET ${ }^{3}$, ANDY SAULTER ${ }^{4}$
}

1. School of Biological and Marine Sciences, University of Plymouth, UK.

timothy.scott@plymouth.ac.uk

2. University of Bordeaux/CNRS, UMR EPOC, Bordeaux, France.

3. IFREMER, Univ. Brest, CNRS, IRD, Laboratoire d'Océanographie Physique et

Spatiale, IUEM, Brest, France

4. UK Met Office, Exeter, UK.

\begin{abstract}
Understanding multi-annual to decadal atmospheric climate controls on winter-wave climate is critical for coastal vulnerability assessment and future development of 'season ahead' forecasting of coastal risk. We examine the relationships between winter-average climate indices (NAO and WEPA) and directional wave power at 63 inshore locations throughout the United Kingdom and Ireland (UK\&I). Analysis of hindcast wave data between 1980-2017 illustrate the extent of directional bi-modality, with $67 \%$ of inshore sites displaying directionally multimodal wave climates. Analysis of directional modes as a function of climatic indices illustrated the control exerted by NAO/WEPA on directional balance of inshore winter wave climate. Along Channel and southern North Sea coasts +WEPA significantly explains winter-averaged wave power for southwesterly wave directional modes $(\mathrm{r}=0.58-0.77)$ and $-\mathrm{NAO}$ significantly explains variability in all easterly wave modes $(\mathrm{r}=-0.6--0.76)$, providing a mechanism for which 'season ahead' inshore wave climate forecasting and rotational beach response can be based.
\end{abstract}

\section{Introduction}

Improved understanding and awareness of how our coasts and beaches will evolve over a range of time scales is critical for effective and sustainable management of our coastal infrastructure. Advances in understanding of coastal evolution and shoreline change require robust knowledge of the forcing wave climate, including spatial, directional, and temporal variability at any given location. The advent of long-term (multi-decadal) atmospheric sea-level pressure records, hindcast directional wave timeseries and beach morphological records have enabled fresh insights into the control multi-decadal atmospheric variability has on inshore wave climate and beach morphological response.

An examination of long-term beach morphological datasets throughout exposed western coasts of Europe by Dodet et al. (2019) highlights the important role of 
winter-averaged waves in controlling local cross-shore shoreline response. Further to this, Castelle et al. (2017) demonstrate that two atmospheric indices, the North Atlantic Oscillation (NAO; Hurrell, 1995), and the newly developed West Europe Pressure Anomaly (WEPA), significantly explain a large amount of exposed west-coast winter wave height variability from Ireland to Portugal. The winter-averaged NAO expressing the strongest relationship north of southern Ireland and winter-averaged WEPA strongest to the south.

Along exposed beaches in the United Kingdom and Ireland (UK\&I), beach response is dominated by on-offshore cross-shore sediment transport that is a function of total wave power (Masselink et al., 2016; Scott et al., 2016; Burvingt et al., 2018). For beaches orientated away from dominant wave approach, incident wave angles are more oblique and morphological changes are increasingly composed of longshore transport processes, with sediment transported in the direction of wave approach (Short and Masselink, 1999); within embayed beach environments the subsequent change in planform orientation is often known as "rotation" (Klein et al., 2002). Harley et al (2011) demonstrated how rotation could be linked to subtle variations in alongshore gradients of wave energy, and hence cross-shore sediment exchange, leading to out-of-phase response at embayment extremities. In contrast, along many (semi) sheltered environments where wave climate is a mix of swell and wind components, the incident wave climate can be directionally bi-modal, and morphological changes can be controlled by the time-integrated balance of wave power from the two directions (Ruiz de Alegria-Arzaburu and Masselink, 2010; Bergillos et al., 2016b; Wiggins et al., 2019).

These (semi-) sheltered rotation-dominated sites often exhibit significant interannual directional variability. Recent research by Wiggins et al. (2019) has indicated that winter-averaged variability in NAO and WEPA may have significant explanatory power in predicting wave direction in semi-sheltered seas. Basin-wide research in the Pacific (Barnard et al., 2015; Mortlock and Goodwin, 2016) uncovered subtle links between El Nino Southern Oscillation (ENSO) modes and wave direction, and subsequent variability in cross-shore beach response. Here we investigate whether climate variability, synthesized here by winter-averaged NAO and WEPA, significantly controls directional balance of alongshore wave power at inshore locations throughout the UK \& Ireland (UK\&I), characterized by directionally bi-modal (semi-) sheltered seas. This study aims to further our understanding of inter-annual climate controls on coastal evolution, critical for developing skillful 'season ahead' forecasts of coastal response. 


\section{Wave climate in the UK and Ireland}

The directional wave climates throughout the UK\&I were analysed at 63 coastal locations ( $20 \mathrm{~m}$ depth) utilizing data from the UK Met Office $8-\mathrm{km}$ WAVEWATCH III third-generation spectral wave model (version 3.14; Tolman, 2009), providing a 3-hourly hindcast of statistical wave parameters for the period 1980-2017. This model is described in detail by Mitchell et al. (2017) and has been extensively validated with directional buoys and satellite altimeters by Saulter (2015). These 63 sites were selected to represent all major stretches of exposed coastline throughout the UK and Ireland (Figure 1), and ranged from the extremely exposed storm-dominated Atlantic west coasts of Ireland and Scotland, to more sheltered locally-derived wind wave dominated regions in the Irish Sea, North Sea and English Channel. The following provides an overview of the annual wave climate in each region between 1980-2017.

\section{North West coast (Atlantic)}

W Ireland and NW Scotland: 11 nodes cover these regions that are exposed to the NE Atlantic Ocean wave regimes. Mean annual significant wave heights $\left(H_{s}\right)$ peak at $2.9 \mathrm{~m}$ and $2.2 \mathrm{~m}$ on the exposed west of Ireland and Outer Hebrides (NW Scotland), respectively. Exposed to Atlantic storms, these regions are the most energetic in the UK\&I with $1 \%$ exceedance significant wave heights $\left(\mathrm{H}_{\mathrm{s} 99 \%)}\right.$ of 7-9 $\mathrm{m}$ on exposed coasts. Semi-sheltered regions are along the Northern Ireland and N Scotland coasts where annual mean $H_{s}$ (and $H_{s 99 \%}$ ) are $1.2 \mathrm{~m}(4.4 \mathrm{~m})$ and $1.7 \mathrm{~m}(6 \mathrm{~m})$, respectively (Figure 1). Annual modal wave directions are from the W-NW $\left(270-280^{\circ}\right.$ in exposed locations and $290^{\circ}$ along north-facing coasts) and are swell-dominated and unimodal, with a slight influence of northern swell from the Arctic along the N Scotland coast (Figure 2).

\section{South West coast (Atlantic)}

SW England and Wales: 13 nodes cover these west coast regions that are exposed to W and SW Atlantic Ocean swells. Mean annual $H_{s}$ peak at $2 \mathrm{~m}$ on the exposed SW of England and $1.2 \mathrm{~m}$ in Wales. In the path of more southerly tracking Atlantic storms, these regions are highly energetic with $H_{s} 99 \%$ of $5.5-$ $6.5 \mathrm{~m}$ on exposed coasts. Sheltered regions are along the Bristol Channel coasts where there is increasing attenuation of Atlantic swell. Annual mean $H_{s}$ (and $\left.H_{s 99 \%}\right)$ are $0.4 \mathrm{~m}(1.6 \mathrm{~m})$ to $1.1 \mathrm{~m}(3.9 \mathrm{~m})$ along Bristol Channel coasts. Annual modal wave directions are from the SW-W (250-280 $)$ and are swell-dominated and unimodal along the exposed coasts, with increasing wave directional spread in the more wind-wave dominated Bristol Channel (Figure 2). 


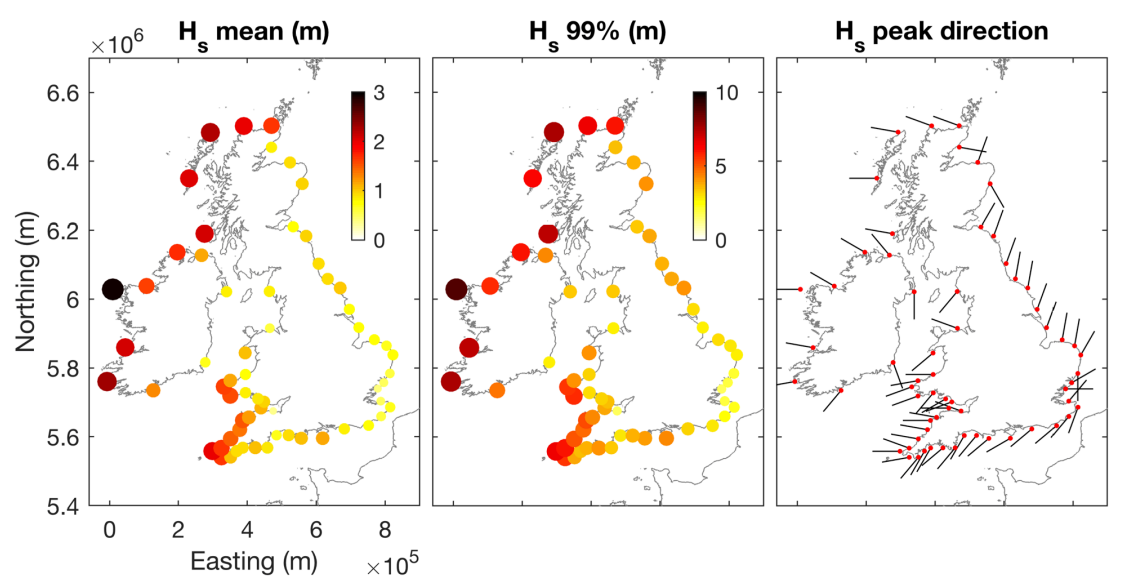

Fig. 1. Round-coast: overview of wave climate 1980-2017 around the UK coast (all 63 MO nodes) - wave height, max wave height $\left(H_{s} 99.5 \%\right)$, peak wave direction (frequency of occurrence).

\section{North Sea}

E England and NE Scotland: 17 nodes cover these east coast regions that are only exposed to northerly ocean swells derived from low pressure systems passing to the north of UK\&I. Inshore wave climate is strongly controlled by coastal orientation and is sensitive to the wind wave regime. Mean annual $H_{s}$ range from $0.5-1 \mathrm{~m}$ and increase to the north. In northern half of the $\mathrm{E}$ coast where there is a significant swell window to the northerly storm waves, $H_{s} 99 \%$ ranges between 3.5-4 m. In more sheltered regions to the southeast $H_{s 99 \%}<3 \mathrm{~m}$. Dominant annual modal wave directions are from the N-NE $\left(10-30^{\circ}\right)$ along the NE coast with increased variability $\left(40-180^{\circ}\right)$ as the coastline rotates to a more southerly exposure in SE England. All regions are directionally multi-modal, increasingly influenced by local wind wave regimes to the south (Figure 2).

\section{English Channel}

South coast of England: 13 nodes cover the south coast region. Influence of SW Atlantic swell waves increase from east to west. Mean annual $H_{s}$ increase from $0.6 \mathrm{~m}$ in the east to $1.2 \mathrm{~m}$ in the west. Atlantic exposure in the west leads to significant variation in storm wave climate with $H_{s 99 \%}$ between 2.9 and $4.3 \mathrm{~m}$ in the western regions and $2.3-3.2 \mathrm{~m}$ in the east. The whole south coast can be considered semi-sheltered and directionally bi-modal with a westerly swell wave component and significant easterly wind wave component. Dominant annual modal wave directions are from the SW (200-240 ) (Figure 2). 

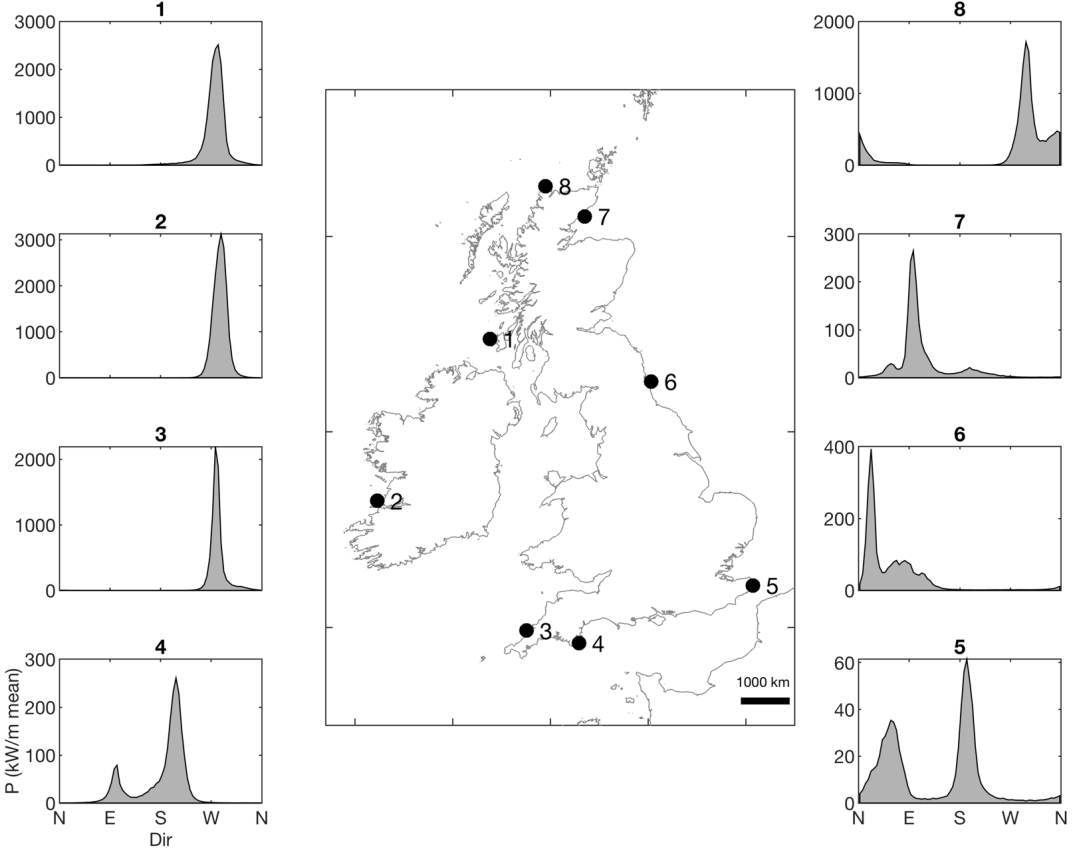

Fig. 2. Example wave climate data from each region of UK\&I demonstrating varying types of directional multi-modality present. Insets show directional power distribution as 1980-2017 3hourly average $\mathrm{kW} / \mathrm{m}$ in $5^{\circ}$ bins.

\section{Irish Sea}

Coasts of NW England, E Ireland and NW Wales: 7 nodes cover this highly variable but sheltered region. Limited influence of S-SW Atlantic swell waves means region is dominated by local wind wave regimes and coastal orientation. Mean annual $H_{s}$ vary from 0.6 to $1.1 \mathrm{~m}$. Away from the influence of Atlantic swell $H_{s 99 \%}$ is between 2.7 and $3.4 \mathrm{~m}$, increasing to $4.2 \mathrm{~m}$ in more exposed locations in W Wales. Many nodes in the region are directionally multi-modal. Dominant annual modal wave directions are highly variable and dependent of local coastal orientation (Figure 2). 


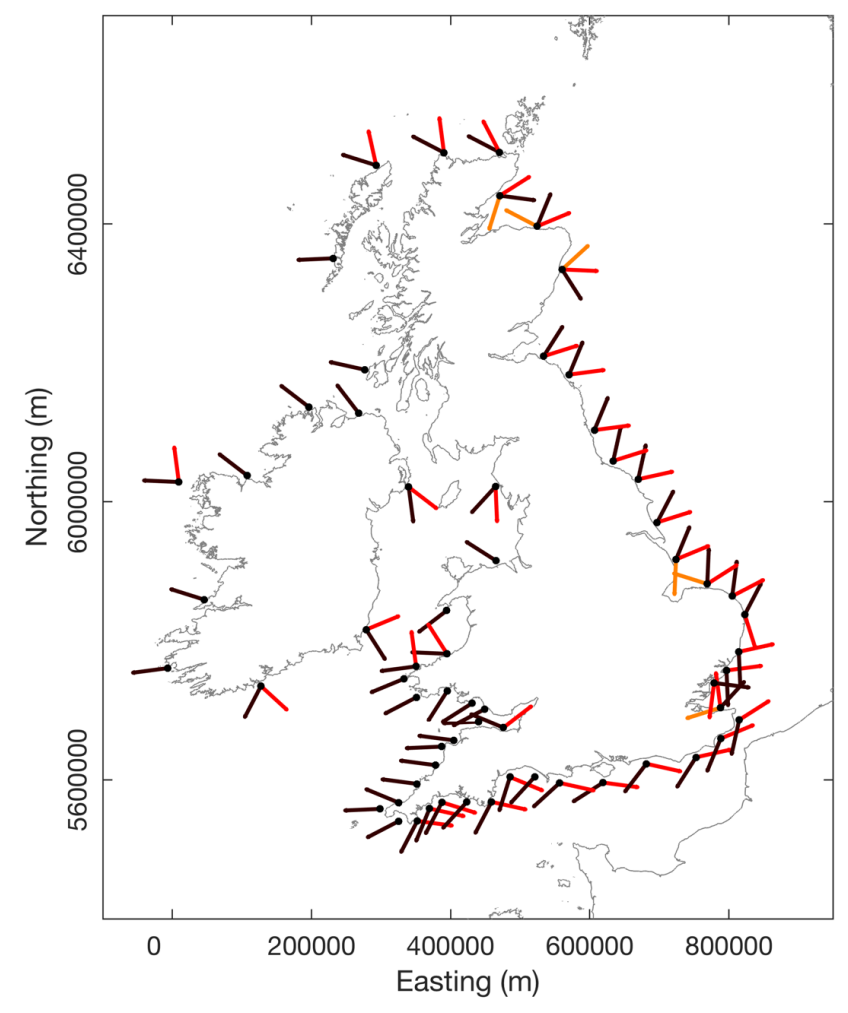

Fig. 3. Directional modes of 1980-2017 cumulative wave power distribution for each wave node around the coast. Black is primary mode, red secondary and orange tertiary. Modes displayed are $>5 \%$ of primary mode peak prominence. Mean primary peak half power width $=22^{\circ}$; therefore, approx. $68 \%(2 \sigma)$ of peak distribution within $20^{\circ}$ of peak.

\section{Wave directional modes}

Figure 2 indicates that beyond the semi-sheltered sites examined in Wiggins et al. (2019; south Devon coast), directionally bi-modal wave climates exist in many inshore regions throughout the coasts of the UK\&I. In order to assess

multimodality throughout the UK\&I and investigate the explanatory power that climate indices have on the directional balance of alongshore wave power at these inshore locations, directional modes were extracted from the cumulative directional wave power distribution for each wave node around the coast and ordered by energy peak. 
Figure 3 shows that 42 of the nodes $(67 \%)$ have directionally multimodal wave climates where secondary modes are $>5 \%$ of primary mode peak prominence. Across all nodes, mean primary peak half power width $=22^{\circ}$; therefore, approximately $68 \%(2 \sigma)$ of peak distribution is within $20^{\circ}$ of peak. All nodes within the English Channel and East Coast regions are directionally multimodal, as well as $37 \%$ of Northwest coast (Atlantic), $8 \%$ of Southwest coast (Atlantic) and $71 \%$ of Irish Sea nodes. Of particular interest are nodes within the English Channel coast and the southern East Coast where primary and secondary modes are from opposing directions with respect to the coastal normal, therefore having the greatest potential to influence coastal morphodynamics with respect to the directional balance of alongshore wave power.

\section{Role of atmospheric indices}

In order to examine the relationships between long-term atmospheric forcing and winter wave climate around the inshore waters of the UK\&I, winteraveraged NAO and WEPA indices were first correlated with total winteraveraged wave power between 1980 and 2017 for each node (Figure 4a \& 4d). For this study, a normalized winter-averaged (DJFM) value of the station-based NAO index (Hurrell et al., 2017) and winter-averaged (DJFM) values of WEPA (Castelle et al., 2017) are utilized (hereafter all references to NAO and WEPA are winter-averaged).

Supporting the findings of Castelle et al. (2017), total winter-averaged wave power was significantly $(\mathrm{p}<0.05)$ positively correlated to NAO in the Atlantic Northwest region $(\mathrm{r}=0.6-0.83)$, but also significantly correlated with all W-NW facing sites in the Southwest coast (Atlantic) and Irish Sea, but with r-values between 0.39-0.58 (Figure 4a). As observed by Castelle et al. (2017), the skill of NAO in explaining total wave power reduces below southern Ireland $\left(\sim 52^{\circ} \mathrm{N}\right)$, below which the skill of WEPA dramatically increases. In fact, WEPA is only significantly positively correlated with nodes in the southern half of the UK\&I and shows highest correlations in the Southwest coast (Atlantic) $(r=0.66-$ $0.79)$ and W English Channel ( $\mathrm{r}=0.81-0.84)$.

While significant positive relationships with NAO and WEPA for Atlantic coasts were expected in the context of previous research, analysis also revealed significant negative correlations with NAO along the predominantly wind-wave dominated east-facing North Sea coast $(\mathrm{r}=-0.28--0.69)$, providing evidence that the inverse relationships between easterly waves and NAO, shown by Wiggins et al. (2019) at Start Bay (western English Channel coast), may be relevant throughout a broader region (Figure 4). 

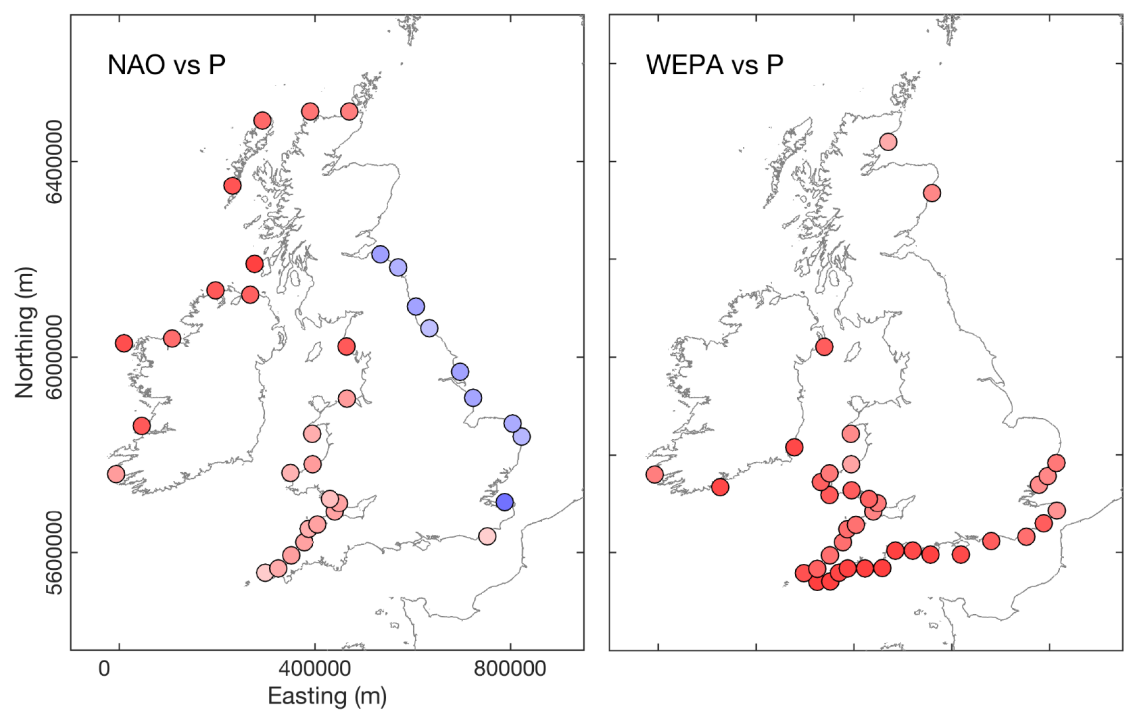

Fig. 4. Correlations between mean winter wave height and wave power with NAO and WEPA around the coast. Only locations where correlation coefficients (r) were significant to $95 \%$ level are shown. Correlations between mean winter wave power and NAO (left) and WEPA (right) around the coast for $\mathrm{N}\left(315-45^{\circ}\right), \mathrm{S}\left(135-225^{\circ}\right), \mathrm{E}\left(45-135^{\circ}\right)$ and $\mathrm{W}\left(225-315^{\circ}\right)$ wave directional sectors. Only locations where correlations (r) are significant at $95 \%$ level $(\mathrm{P}<0.05)$ are shown.

To explore further the relationships with wave directional modes, winter (DJFM) cumulative wave power associated with local directional modes (angular window of $20^{\circ}$ either side of power modal peak) were investigated as a function of WEPA and NAO (see Figure 3). Strikingly, results in Figure 5 show that NAO and WEPA explain a significant amount of variability in winteraveraged waves throughout UK\&I, even in regions away from Atlantic swell waves where local wind wave regimes dominate. In many cases multiple directional modes have contrasting and highly significant atmospheric controls.

All nodes in the English Channel and southern North Sea coasts (south-facing) are strongly directionally bi-modal (Figure 3), with coastal orientation suggesting dominance of alongshore sediment transport processes. Analysis shows that WEPA significantly explains variability in winter-averaged wave power for all southwesterly wave directional modes $(\mathrm{r}=0.58-0.77)$ and NAO explains variability in all easterly wave modes $(\mathrm{r}=-0.6--0.76)$. 


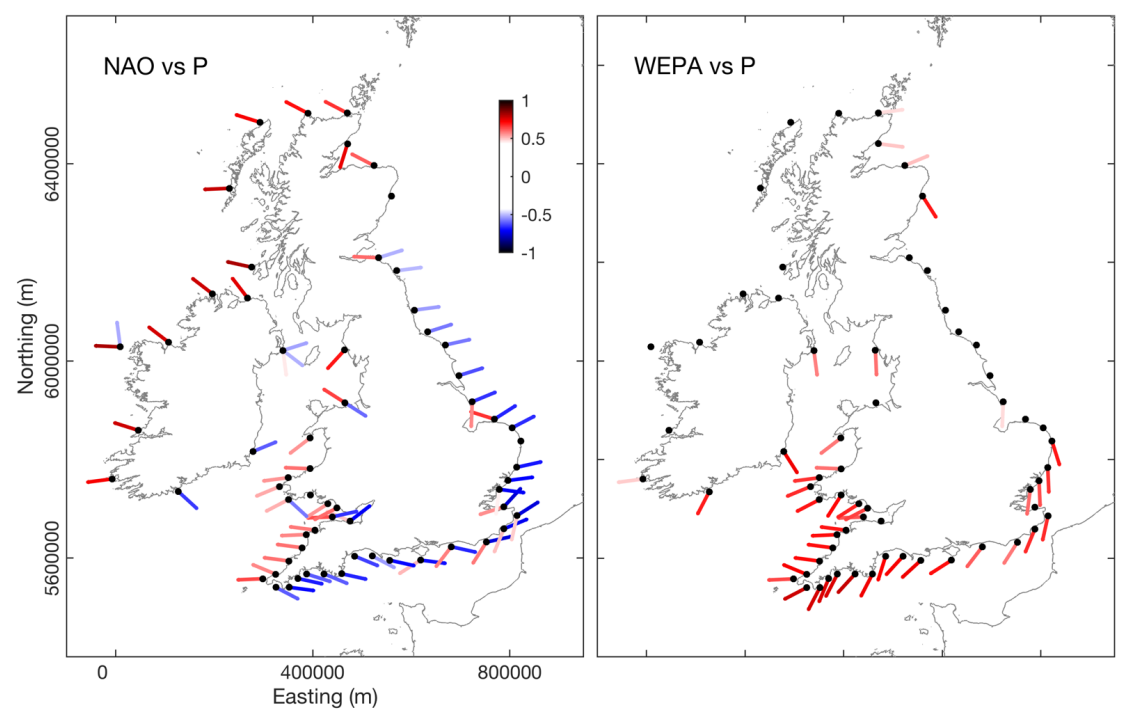

Fig. 5. Relationship between winter NAO/ WEPA (left panels) and directional winter wave power for 63 wave nodes around the coast of the UK \& Ireland (1980-2017). Relationship between winter NAO/WEPA (right panels) with local wave directional modes $\left(+/-20^{\circ}\right)$ for each node. Colors are correlation coefficients, only results where $\mathrm{P}<0.05$ are shown.

Beyond the south coast regions, easterly-directed wave modes throughout the North Sea region, characterized by short wind waves, showed significant relationships with $-\mathrm{NAO}(\mathrm{r}=-0.44-0.76)$ decreasing to the north. Interestingly, neither NAO nor WEPA had any skill in explaining northerly swell waves entering this North Sea region.

Throughout the UK\&I, WEPA had significant skill in explaining southerly directed wave directional modes, both those characterized by Atlantic swell waves and locally-derived wind waves. The strongest influence of WEPA was in the southern half of the UK\&I, below $53^{\circ} \mathrm{N}$ (level with N.Wales). NAO on the other hand has strong explanatory power across the domain, with $\mathrm{NAO}+$ driving an increase in wave power from $\mathrm{W}-\mathrm{NW}$ throughout the west-facing coasts, and NAO- linked with NE-SE waves (most likely linked with easterly dominated airflow) throughout.

\section{Characterisation of regional response}

The skill of WEPA and NAO in explaining variability in the directional wave power balance throughout the bimodal nodes in the UK\&I is illustrated in Figure 6. A Wave Directional Index (WDI) is computed following Wiggins et 
al. (2019), which represents the winter-averaged normalized wave power balance between two opposing wave directional modes, shown by Wiggins et al. (2019) to correlate to beach rotation (Figure 6). For all 8 example sites shown in Figure 6, WDI time-series show significant temporal variability over a 20-year period. Periodicity in WDI along west and south coast regions (sites 1-5; Figure 6) displays a $<10$-year cyclicity. WDI at these sites is significantly positively correlated with NAO (all sites) and WEPA (south-facing sites) and the periodicity is in range of that of NAO and WEPA shown by Castelle et al. (2018) through wavelet analysis. In contrast, the north-facing North Sea example sites show a strong $>10$-year periodicity in WDI, with weak or little correlation to the climatic indices tested.

Examining winter WDI values in WEPA-NAO parameter space provides some further insights into regional response in the directionally bimodal examples sites in Figure 6. South-facing sites below $53^{\circ} \mathrm{N}$ (sites 2, 4 and 5) are characterized by strong positive WDI (above average southwesterly wave power contribution) under a combination of +NAO and +WEPA, but tend to show neutral or negative WDI (above average easterly wave power contribution) under all other combinations. In contrast, variability in WDI at north-facing sites throughout UK\&I (sites 3, 6, 7 and 8) is best explained by NAO, but the response characteristics are somewhat variable dependent on location. Sheltered north-facing sites in the west, like site 3 in the Bristol Channel, experience westerly waves dominance under +NAO and easterly under -NAO, largely driven by impacts of NAO on local wind regime. But, the WDI at the northfacing sites in the North Sea is responding only to the relationship between easterly waves and -NAO, leaving the dominant northerly swell component of directional climate unexplained and hence the WDI timeseries has only weak correlation to NAO.

In summary, this analysis has shown that the winter-averaged climate indices NAO and WEPA have significant skill in explaining variability in directional wave climate throughout the UK\&I. There is particularly strong explanatory power within (semi-) sheltered south-facing coasts, below $53^{\circ} \mathrm{N}$ (level with N.Wales), where winters with combined +WEPA and +NAO are associated with southwesterly wave power dominance, and winters with-NAO, regardless of WEPA are easterly wave power dominated. This is significant for coastal morphodynamics at these sites as: (1) the second directional mode typically contributes $>20 \%$ of the peak prominence of primary mode; and (2) primary and secondary modes are from opposing directions with respect to the coastal normal. Therefore variability in alongshore wave power balance has a real influence on beach rotation. 

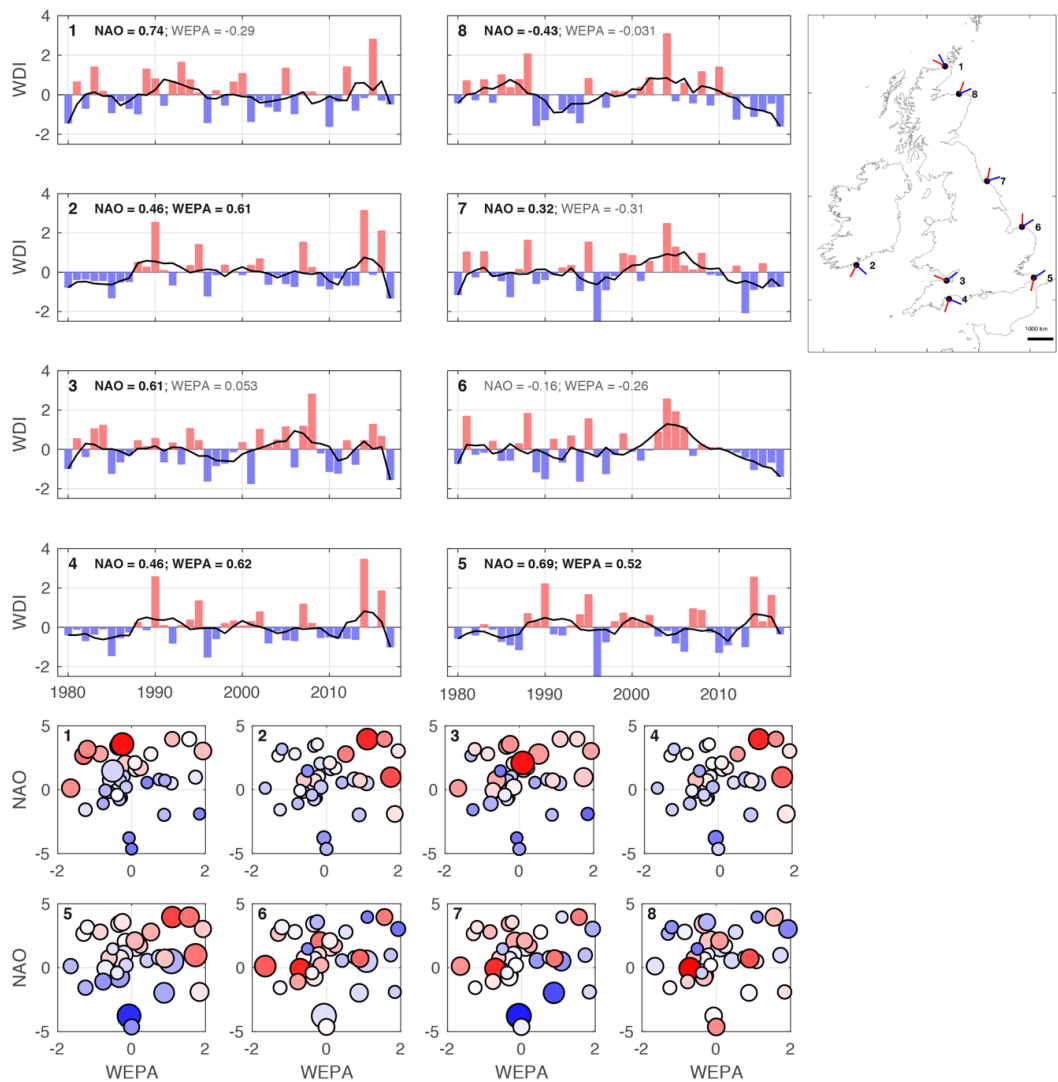

Fig. 6. Temporal variability of Wave Direction Index (WDI) for 8 example sites that are located in sheltered coastal locations throughout the UK\&I. Top left panels show winter-averaged WDI timeseries with 5-year running mean, for each site correlations with winter-averaged NAO and WEPA are shown (bold is significant at the 95\% level). Bottom left panels show annual winteraveraged WDI values within associated WEPA-NAO parameter space. Color is WDI value (low to high is blue to red, white is zero), bubble size is standardized winter wave power for the associated year. Top right panel is UK\&I map showing site locations and primary and secondary modes used, where WDI is positive (red) then primary wave directional mode is dominating (red).

\section{Conclusions}

This work examined the role of winter-averaged climate indices WEPA and NAO in explaining variability in the directional wave climate throughout the UK\&I. Using a hindcast wave record spanning 40 years (1980-2017) the study provides new insights into potential climatic controls of multi-annual shoreline variability and highlights the huge potential of using climate indices to support 
coastal management practices, with assessment of NAO and WEPA 'season ahead' forecast skill for explaining winter-wave forcing the next step.

The key findings are: (1) $67 \%$ of inshore sites examined displayed directionally multimodal wave climates (where secondary modes are $>5 \%$ of primary mode peak prominence), with all sites within the English Channel and North Sea regions found to be directionally bimodal; (2) along the English Channel and the southern North Sea coasts primary and secondary modes are opposing with respect to the coastal normal and have the greatest potential to influence coastal morphodynamics with respect to the directional balance of alongshore wave power; and (3) analysis of directional modes as a function of climatic indices illustrated the control exerted by NAO and WEPA on directional balance of inshore winter wave climate. Along the Channel and southern North Sea coasts the combination of +WEPA and +NAO significantly explained winter-averaged wave power variability for southwesterly wave directional modes and -NAO significantly explains variability in all easterly wave modes, providing a mechanism for which 'season ahead' inshore wave climate forecasting and rotational beach response can be based in this region.

\section{Acknowledgements}

The authors would like to thank the UK Met Office for making available hindcast wave data. Station-based NAO Index Data provided by the Climate Analysis Section, NCAR, Boulder, USA and WEPA records were provided by Bruno Castelle. This research was funded by NERC through a Strategic Highlight Topics grant (Physical and biological dynamic coastal processes and their role in coastal recovery (BLUE-coast) NE/N015525/1). GD is supported by ESA under the Sea State CCI project. BC funded by SONO (ANR-17-CE010014) through the Agence Nationale de la Recherche (ANR).

\section{References}

Barnard, P.L., and many others, 2015. Coastal vulnerability across the Pacific dominated by El Niño/Southern Oscillation. Nat. Geosci. 8, 801.

Bergillos, R.J., Ortega-Sánchez, M., Masselink, G., Losada, M.A., $2016 \mathrm{a}$. Morpho-sedimentary dynamics of a micro-tidal mixed sand and gravel beach, Playa Granada, southern Spain. Mar. Geol. 379, 28-38.

Burvingt, O., Masselink, G., Scott, T., Davidson, M., Russell, P., 2018. Climate forcing of regionally-coherent extreme storm impact and recovery on embayed beaches. Mar. Geol. 401, 112-128. 
Castelle, B., Dodet, G., Dodet, G., Scott, T., 2017b. A new climate index controlling winter wave activity along the Atlantic coast of Europe: the West Europe Pressure Anomaly. Geophys. Res. Lett. 44, 1384-1392.

Castelle, B., Dodet, G., Masselink, G., and Scott, T. (2018). Increased wintermean wave height, variability, and periodicity in the Northeast Atlantic over 1949-2017, Geophysical Research Letters, 45(8), 3586-3596.

Dodet, G., Castelle, B., Masselink, G., Scott, T., Davidson, M., Floc'h, F., Jackson, D., and Suanez, S. (2018). Beach recovery from extreme storm activity during the 2013/14 winter along the Atlantic coast of Europe. Earth Surface Processes and Landforms

Harley, M.D., Turner, I.L., Short, A.D., Ranasinghe, R., 2011. A reevaluation of coastal em- bayment rotation: the dominance of cross-shore versus alongshore sediment trans- port processes, Collaroy-Narrabeen Beach, southeast Australia. J. Geophys. Res. Earth Surf. 116, 1-16.

Hurrell, J. W. (1995), Decadal Trends in the North Atlantic Oscillation: Regional Temperatures and Precipitation, Science, 269(5224), 676-679

Klein, A.H.D.F., Filho, L.B., Schumacher, D.H., 2002. Short-term beach rotation processes in distinct headland bay beach systems. J. Coast. Res. 18, $442-458$.

Masselink G, Castelle B, Scott T, Dodet G, Suanez S, Jackson D, Floc'h F. 2016a. Extreme wave activity during 2013/2014 winter and morphological impacts along the Atlantic coast of Europe. Geo- physical Research Letters 43: 2135-2143.

Mortlock, T.R., Goodwin, I.D., 2016. Impacts of enhanced central pacific ENSO on wave cli- mate and headland-bay beach morphology. Cont. Shelf Res. 120, 14-25.

Ruiz de Alegria-Arzaburu, A., Masselink, G., 2010. Storm response and beach rotation on a gravel beach, Slapton Sands, U.K. Mar. Geol. 278, 77-99.

Tolman, H.L., 2009: User manual and system documentation of WAVEWATCH IIITM version 3.14. - NOAA/NWS/NCEP/ MMAB Technical Note 276, Environmental Modeling Cen- ter, Marine Modeling and Analysis Branch, 
Saulter, A., 2015: Assessment of WAM Cycle-4 based source terms for the Met Office global-regional wave modelling system. - Forecasting Research Techni- cal Report 598, Met Office, Exeter, UK.

Scott, T., Masselink, G., Hare, T.O., Saulter, A., Poate, T., Russell, P., Davidson, M., Conley, D., 2016. The extreme 2013/2014 winter storms: beach recovery along the southwest coast of England. Mar. Geol. 382, 224 241.

Short, A.D., Masselink, G., 1999. Handbook of beach and shoreface morphodynamics. Embayed and Structurally Controlled Beaches. John Wiley.

Wiggins, M. A., Scott, T., Masselink, G., Russell, P., and McCarroll, R. (2019). "Coastal embayment rotation: Response to extreme events and climate control, using full embayment surveys," Geomorphology, 327, 385-403. 